\title{
Research on the Traction Substation Computer Aided Modeling and Simulation based on Virtual Instrument Technology
}

\author{
Mouhua Ren ${ }^{1}$ \\ ${ }^{1}$ Lanzhou Jiaotong University, \\ Lanzhou,Gansu,730070 China
}

\begin{abstract}
In this paper, we conduct research on the traction substation computer aided modeling and the simulation based on virtual instrument technology. It the powerful function of computer system, combined with the corresponding hardware which adopts modular structure, greatly breaks through traditional instrument in data processing. Electric traction power supply supervisory system overall joint debugging can only wait for engineering site communication can only be carried out under the condition of debugging. Our designed system simulated the modelling process well. In the near future, more related research will be down to modify the current method.
\end{abstract}

Keywords: Computer Aided Modeling; Traction Substation; Virtual Instrument; Simulation.

\section{Introduction}

In the field of virtual instrument technology is the computer aided testing an important new technology. Virtual instrument is on general computer platform, users according to their requirement definition and design of the instrument testing capabilities, the essence of which is the traditional instrument hardware and fully combined with the latest computer software and hardware technology, in order to realize and expand the function of traditional instruments. It is a kind of based on graphics development, debugging and running the program of the integrated environment. In today's information age the rapid development of computer hardware to software technology from every level led technology from all walks of life and the development of virtual instrument system based on computer technology is with the power of the irreversible pushes the revolutionary tradition of measurement and control technology of measurement and control system based on hardware or software of solidification more give priority to Single function and low reliability of the hardware is the concept of virtual instrument system is not only the main defect of it promote the improvement of instrument based measurement and control system at the same time also affected, which is mainly composed of data acquisition to the evolution of the traditional construction method of measurement and control system. As a new generation of instrument technology, virtual instrument has many characteristics, the application of economic and social fields has produced important influences on both. Virtual instrument to realize the complexity and comprehensive measurement, measurement precision further, greatly overcome the limitations of traditional instruments.

Concept of virtual instrument system is to break through the traditional concept of instrument, is the combination of the computer system and instrument system technology. It the powerful function of computer system, combined with the corresponding hardware, adopts modular structure, greatly breaks through traditional instrument in data processing, display, transmission, storage and other constraints, the user can easily for maintenance, expansion, upgrades and to achieve the resource sharing system, reduces the cost, won the majority of engineering and technical personnel, and shows strong vitality and to promote and accelerate the further combination of instrument technology and computer technology. Virtual instrument using standard computer and monitor instead of 
the traditional instruments in the input, processing, and output unit, and combined with the service in the implementation of measurement software system and data acquisition system to realize all kinds of test and measurement task. Function of virtual instrument is designed by the user and definition, minimizing the instrument hardware core, modular and software, using the powerful data processing ability of computer system to complete data acquisition, control, analysis and processing, test results through the virtual panel output with a variety of forms [1-3].

Computer friendly human-computer interaction convenient online help in time of powerful data and graphics processing capability of large capacity storage function and display printing which will make up for the deficiency of the traditional instruments so it appears to the development of test instruments and innovation has opened up a new world compared with the traditional recorder of mass data storage instrument development time greatly reduce the price more competitive instrument performance improve faster, smaller physical size and higher flexibility as long as add function modules of the system software expand functions can meet the demand of users to the new. In the figure one, we show the sample application of virtual instrument technology.

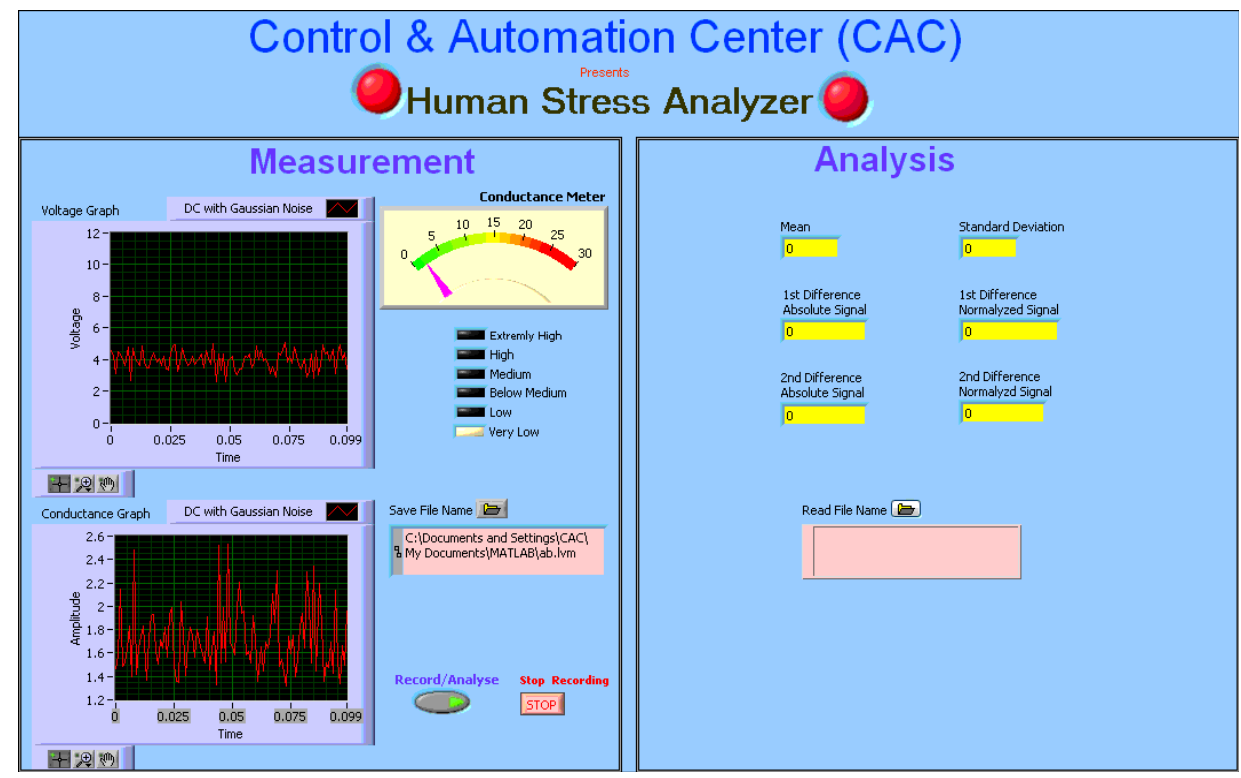

Figure 1. The Sample Application of Virtual Instrument Technology

In this paper, we conduct research on the traction substation computer aided modeling and the simulation based on virtual instrument technology. Electric traction power supply supervisory system overall joint debugging can only wait for engineering site communication can only be carried out under the condition of debugging conditions are so the overall performance of the scheduling management automation system will not be able to get timely play many potential problems in the system also cannot be exposed in the rush of debugging so to develop a can be used in electric power dispatching automation management system development and debugging of the electric power dispatching end integrated automation system simulation platform is very necessary.

\section{Our Proposed Methodology and Theory}

The Basic Knowledge on Traction Substation. Traction substation integrated automation system is the use of computer technology, modern communication technology, through a variety of function combination and optimization design of 
the substation secondary equipment to perform automatic monitoring, measurement, control and coordination of a kind of comprehensive automation system. It is a kind of modern technology and equipment of substation, is in the substation automation and computer and communication technology in the field of integrated application which is to realize the traction substation unattended or less people on duty and reliable technical support. Electrification traction substation integrated automation system adopts the hierarchical distributed network structure, the traction substation as the core, with function of module, will the traction power supply facilities into the system of the power supply arm connecting nodes, fully embody the decentralized control, centralized management model of structure. Control and protection system which is mutually independent and related information sharing each other again plays important roles.

Management is the actual operation of reference traction substation design are responsible for the management of a substation all simulation objects such as telemetry remote communication object management and protection of object management for automatic monitoring measurement to the full traction substation main equipment of the automatic control and related microcomputer protection simulation. Traction substation automatic input device of standby power supply and standby equipment installed by the following regulation: twice the power supply into line traction substation should furnish standby power automatic input device. When the traction substation of the traction transformer using fixed standby mode, two sets of traction transformer should be installed automatic input device. Interval main realization of substation equipment management all the protection object of the realization of the function of management and the corresponding simulation substation protection devices can be classified as according to the functional category change main protection and back-up protection into different categories such as line protection feeder protection and capacitor protection devices of different functional requirements and implementation details. In the figure two, we show the traditional topology of the traction substation structure and organization.

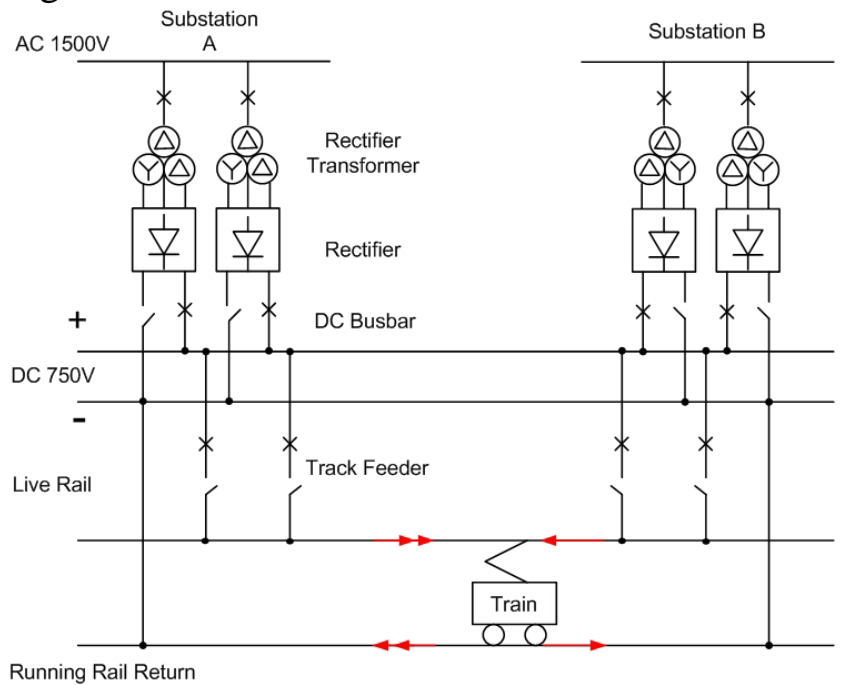

Figure 2. The Traditional Topology of the Traction Substation Structure and Organization

The Virtual Instrument Technology and Applications. The concept of virtual instrument system is the measurement and control system of abstract both traditional and virtual instrument Their function is the same: to collect data to analyze the collected data Then show different results between them mainly reflects in the flexibility of virtual instrument is defined by users themselves this means that the user can freely combine computer platform hardware and software as well as a variety of accessories and the flexibility of application system need by the supplier define function is fixed on the traditional instruments of independence. Virtual instrument technology is not simply a technology by software instead of hardware it is with the general development of computer hardware and software technology and the inevitable result of the widely used of computer as well as measurement and control system for a variety of measuring instruments and equipment put forward the higher request of the wide 
application of virtual instrument technology originated from all walks of life or measuring and testing system for electric parameters of the electric parameters can be measured.

The emergence of virtual instrument technology has broken the traditional instruments thoroughly defined by the manufacturer, the user can change the mode, the user with the aid of universal instrument hardware platform, calls the different test software, can form different function of the instrument. Virtual instrument can provide users with a full play to their talents and imagination of space, the user can follow one's design and construct their own in order to satisfy the demands of a wide variety of test instrument system. In virtual laboratory, the experiment, according to the project must be through a user interface for students to nonlinear browsing, the experimenters must through a user interface to interact with virtual experiment system. Therefore, building a friendly interface, convenient operation, approaches the human-machine interface of the physical prototype is to solve the primary problem of virtual laboratory. Through the virtual experiment interface should not only make people feel in the situations to solve practical problems, and to realize the discovery experimental problems and seek the solution actual problem solution process a sense of achievement. In the stage of process modeling and simulation, virtual experiment is subjects by observing the experimental phenomena, analysis of the experimental results, the processing experimental data, realize the experimental process, and according to the feedback adjustment experiment strategy, clarification experiment, testing the hypothesis that the experimenter and experiment scheme.

The Sample Structure for Traction Substation Computer Aided Modeling. Traction substation integrated automation system is mainly for the purpose of complete protection, power calculation and monitoring, reliability and sensitivity of the system, such as real-time requirements to the rational allocation of system function. During normal operation, the on-line monitoring of traction network operation and running state of equipment. The control unit can be controlled by the distance or local monitoring machine or emergency line selection device to control, through comprehensive control machine operation in the upper of this substation circuit breaker, isolating switch operation. Superior comprehensive control machine send move to accept the control center, according to the specific control commands required to make into the alleged corresponding control unit to realize the operation control and data acquisition. Superior comprehensive control machine and power switch signal data returned from the substation control center.

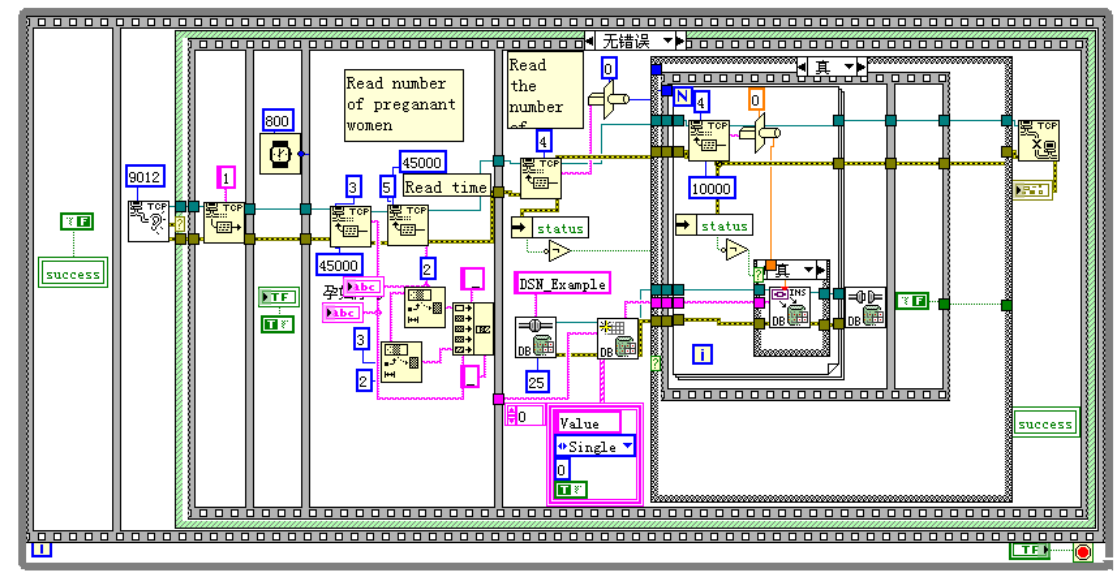

Figure 3. The Sample Structure for Traction Substation Computer Aided Modeling 


\section{CONCLUSIONS}

In this paper, we conduct research on the traction substation computer aided modeling and the simulation based on virtual instrument technology. With the rapid development of national economy, electrified railway in the construction and retrofit, almost all of the traction substation transformation and new will adopt integrated automation system. Virtual instrument technology is not simply a technology by software instead of hardware it is with the general development of computer hardware and software technology and the inevitable result of the widely used of computer as well as measurement and control system. Traction substation integrated automation technology itself for railway electrification of professional counterparts, also belong to a new topic, the selection principles and methods of traction substation integrated automation system for the determination of it is very necessary. Our proposed methodology solves the issues well.

\section{References}

[1] Quan X, Zhou N. Research on digital circuit experimental system based on virtual instrument technology[J]. Experimental Technology \& Management, 2014.

[2] Fan J L, Liu J. Distributed Monitoring System Based on Virtual Instrument Technology for Electric Vehicle Charging Stations[J]. Electrical Measurement \& Instrumentation, 2014.

[3] Li-Na L I, Liang D S, Zhi T U, et al. Transistor Characteristics Measurement Based on Virtual Instrument Technology[J]. Journal of Liaoning University, 2014. 